\title{
The Impact of the Extra-Costs on the Global Cost of Credit
}

\author{
Simone Landini ${ }^{1}$, Luisa Tibiletti ${ }^{2} \&$ Mariacristina Uberti $^{2}$ \\ ${ }^{1}$ IRES Piemonte, Socioeconomic Research Institute of Piedmont, Italy \\ ${ }^{2}$ Department of Management, School of Management and Economics, University of Torino, Italy \\ Correspondence: Mariacristina Uberti, School of Management and Economics, Department of Management, \\ University of Torino, C.so Unione Sovietica 218 bis, 10134 Torino, Italy. E-mail: mariacristina.uberti@unito.it
}

Received: May 4, 2020

doi:10.5539/ijbm.v15n7p173
Accepted: May 30, 2020

Online Published: June 12, 2020

URL: https://doi.org/10.5539/ijbm.v15n7p173

\begin{abstract}
In this note, we analyze the impact of the extra-costs payment schedule on the Effective Annual interest Rate $(E A R)$, one of the most popular global cost measures of consumer credit loan payments. First, we prove that the $E A R$ can be expressed by the financing credit interest rate with an extra-costs interest rate addendum, and we investigate the drivers of this latter. We show that the extra-costs interest rate decreases if extra-costs payments are postponed. Consequently, the $E A R$ is minimum if extra-costs are charged in a lump sum at the expiry date of the contract and maximum if they are charged in a lump sum at the contract beginning time. To explain how the schedule of payments impacts on the $E A R$, we develop a sensitivity analysis through illustrative applications. We also highlight that $E A R$ depends on the timing of extra-costs payments. In particular, we show that $E A R$ decreases with the increase in the Modified Duration of the cash flow of extra-costs. The results of the paper are useful to provide decision-makers a better awareness about how to spread the extra-costs payments during the contract lifetime and, therefore, to define the structure of consumer credit loan payments to supervise the global cost of the financing.
\end{abstract}

Keywords: effective annual interest (EAR), extra-costs, global cost of credit, modified duration

\section{Introduction}

In financial practice, consumer payment credits contracts require payment of extra-costs spread over the contract lifetime. At the beginning of the fixed-term contract, the parties agree on the extra-costs amount and their temporal payment schedule over the contract lifetime. The agreed terms' effect on the global cost of credit is measured by the Effective Annual interest Rate (EAR) (see, for example, Disney \& Gathergood, 2013). To make an evidence of the $E A R$ drivers, we achieve an approximation that is equal to the financing credit interest rate plus an extra-costs interest rate. Our analysis shows the dependence of this latter addendum on extra-costs size and schedule of payments. This two-dimensional information can be summarized by the Modified Duration of the extra-costs payments stream. We show that the EAR decreases if the extra-costs payments accrued by the interests computed at the financing credit rate are postponed over time. As a consequence, the EAR is maximum if discounted extra-costs are charged in a lump sum at the contract beginning time and minimum if accrued extra-costs are charged in a lump sum at the contract expiry date. Formulae become more straightforward if the contract involves periodic payments of a constant amount. Some simulations assess the robustness of our results.

The remainder of the paper is organized as follows. In Section 2, the notation is set up. In Section 3, we achieve an $E A R$ approximation. Section 4 presents our results through simulations and discusses the outcomes of some sensitivity tests. Section 5 concludes the note. The proofs are reported in the Appendix.

\section{Notation and Layout of the Model}

Let

- $\quad F$ be the initial debt financing at time 0 ;

- $\quad r$ be the annual compound financing contractual interest rate;

- $\quad n$ be the number of contract's payments; for the ease of explanation, we assume that the payments are paid annually and so $n$ coincides with the contract expiry date;

- $f_{s} \geq 0$ be the contractual payment due at the time $s$, with $s=1, \ldots, n$, to pay back the initial debt $F$ within the contract expiry date $n$. Each $f_{s}$ is the sum of the capital share and the interest share, and the payments are 
not necessarily of equal amounts; therefore, a non-level series of payments can be involved;

- $\quad c_{s} \geq 0$ be the extra-costs due at the time $s$, with $s=0,1, \ldots, n$ and $c_{0} \leq F$;

- $\quad R_{0}=F-c_{0}$ be the net cash flow at the time 0 ;

- $\quad R_{s}=f_{s}+c_{s}$, be the global payment due at the time $s$, with $s=1, \ldots, n$.

The primary contract conditions are assumed to hold, see, for example, Brealey, Myers \& Allen (2014) and Magni (2020, and the literature cited therein). Let the Net Present Value (NPV) of the financing be

$$
N P V_{F}(x)=F-\sum_{s=1}^{n} \frac{f_{s}}{(1+x)^{s}}
$$

where $x$ is the interest preference rate for valuing the series of cash flows at time 0 . By construction, the payments $f_{s}, s=1, \ldots, n$ satisfy the equation of value at time 0

$$
N P V_{F}(r)=F-\sum_{s=1}^{n} \frac{f_{s}}{(1+r)^{s}}=0
$$

for the internal rate of return $r$ of the financing contract.

Let $N P V_{\text {Extra costs }}$ be the $N P V$ of the extra-costs $c_{s} \geq 0$ with $s=0,1, \ldots, n$

$$
N P V_{\text {Extra costs }}(x)=c_{0}+\sum_{s=1}^{n} \frac{c_{s}}{(1+x)^{s}}
$$

where, as before, $x$ is the interest rate for discounting the cash flow of each extra cost.

The discounted cash flow of the total cash flows is given by

$$
N P V_{\text {Global cost }}(x)=N P V_{F}(x)-N P V_{\text {Extra costs }}(x)=\left(F-c_{0}\right)-\sum_{s=1}^{n} \frac{f_{s}+c_{s}}{(1+x)^{s}}
$$

By definition, the Effective Annual Interest Rate $(E A R)$ of the contract complies the condition (Note 1)

$$
N P V_{\text {Global cost }}(E A R)=0
$$

In general, no closed formula exists for $E A R$, to overcome this limitation, we achieve an analytical approximated measure for $E A R$ in the following Section.

\section{An "Extra-Costs Interest Rate Addendum."}

In this section, we develop an approximated measure of $E A R$ given by the financing credit interest rate $r$ and an extra-costs interest rate addendum.

THEOREM 1. An analytical approximated measure for the EAR

Let the initial debt $F$ be financed at the credit interest rate $r$. The financing contract includes the payments $f_{s}$ satisfying (1) and the cash flows of extra-costs $c_{s}$ at times $s=0,1, \ldots, n$, with $c_{0} \leq F$. Then the EAR admits the following approximated measure (Note 2)

$$
E A R_{\text {proxy }}=r+\mathcal{E} ; \quad \varepsilon=\frac{N P V_{\text {Extra costs }}(r)}{F \cdot D_{F}+C \cdot D_{\text {Extra costs }}}
$$

where $\varepsilon$ is called the "extra-costs interest rate addendum," and

- $\quad C=\sum_{s=1}^{n} \frac{c_{s}}{(1+r)^{s}}$ is the present value at the financing interest rate $r$ of the future extra-costs $c_{s}$ with $s=1, \ldots, n$;

- $\quad D_{F}=\frac{\sum_{s=1}^{n} s \cdot f_{s} \cdot(1+r)^{-s}}{(1+r) \cdot F}$, with $\frac{1}{1+r} \leq D_{F} \leq \frac{n}{1+r}$ is the Modified Duration of the contract payback of the initial debt $F$ at the financing interest rate $r$;

- $D_{\text {Extra costs }}=\frac{\sum_{s=1}^{n} s \cdot c_{s} \cdot(1+r)^{-s}}{(1+r) \cdot C}$ is the Modified Duration of the extra-costs at the financing interest rate $r$ and 
there exists at least one $c_{s} \neq 0$, with $s=1, \ldots, n$, and $\frac{1}{1+r} \leq D_{\text {Extra costs }} \leq \frac{n}{1+r}$; and

- $D_{\text {Extra costs }}=0$ if $c_{s}=0$ for all $s=1, \ldots, n$.

Proof. See the proof in Appendix A.

For a review of the use of the duration in the literature, see Shah, Sukmana, and Fianto (2020). It is worth pointing out that $E A R=r$ if and only if there are no extra-costs neither at the initial time nor subsequently, i.e., $c_{0}=0$ and $c_{s}=0$ at all times $s=1, \ldots, n$.

Remark 1. Repayment of consumer credit via amortization with level payments and equal amounts of periodic extra-costs

The relationship of $E A R_{\text {proxy }}$ in Equation (3) becomes more straightforward if the contract involves $n$ periodic global cash flows of equal amounts of payments. Let the credit reimbursement be made via amortization with level payments, i.e., the repayment is structured in these equal payments

$$
f=f_{s}=\frac{F}{\left.a_{\bar{n}}\right|^{r}} \quad \text { for } s=1, \ldots, n
$$

where $a_{\bar{n} \mid r}=\frac{1-(1+r)^{-n}}{r}$ denotes the present value of an annuity of $\mathrm{n}$ payments of 1 per period. Let us assume that the amount of the initial extra-costs is $c_{0}$ and the subsequent extra-costs are due in equal amounts $c=c_{s}$ at times $s=1, \ldots, n$. Accordingly, the global periodical payments are of an equal amount $R=f+c$ at times $s=1, \ldots, n$.

The Modified Duration of a series of cash flows with equal amounts of payments is independent on amounts' size (see Dierkes \& Ortmann, 2015). Therefore, the Modified Duration D of the global cash flow is the same as the Modified Durations $D_{F}$ of the contract level payments and $D_{\text {Extracosts }}$ of the extra-costs payments

$$
D=D_{F}=D_{\text {Extra costs }}=\frac{1+\frac{1}{r}-\frac{n}{(1+r)^{n}-1}}{1+r} \quad, \quad \text { with } \frac{1}{1+r} \leq D<\frac{1}{r}
$$

Using Equation (4), Equation (3) is reformulated as

$$
E A R \cong r+\varepsilon \quad \text { with } \varepsilon=\frac{N P V_{\text {Extra costs }}(r)}{D \cdot(F+C)} .
$$

Being $N P V_{\text {Extra costs }}(r)=c_{0}+C$, the "extra-costs interest rate addendum" can be rewritten as

$$
\varepsilon=\frac{N P V_{\text {Extra costs }}(r)}{D \cdot\left[N P V_{\text {Extra costs }}(r)+\left(F-c_{0}\right)\right]}
$$

where $F-c_{0}$ is the net financing cash flow at the initial time.

\section{The Minimum and Maximum for $E A R_{\text {proxy }}$}

Let us assume that the parties agree on customizing the extra-costs payment timing, under the condition that if a payment is anticipated, then the due amount is discounted at the financing interest rate $r$. If the payment is deferred, then the due amount is accrued at the financing interest rate $r$. More formally, if the payment $c_{s}$ is paid:

- $\quad m$ periods in advance concerning the scheduled time $s$, then the due amount to be paid is the discounted amount $\frac{c_{s}}{(1+r)^{m}}$;

and if the payment $c_{s}$ is paid

- $\quad m$ periods after the scheduled time $s$, then the accrued amount to be paid is $c_{s} \cdot(1+r)^{m}$.

That means that any extra-costs payment $c_{s} s=1, \ldots, n$ can be anticipated or postponed by properly discounting or capitalizing. Therefore, the extra-costs stream has to comply with the condition

$$
N P V_{\text {Extra costs }}(r)=c_{0}+C \text {. }
$$


THEOREM 2. The minimum and maximum for EAR approximation (3)

Let the initial debt $\mathrm{F}$ and the extra-costs be financed at the financing interest rate $r$ and $N P V_{\text {Extra costs }}(r)=c_{0}+C$. The EAR approximation decreases in the extra-costs Modified Duration $D_{\text {Extracosts }}$. Then, the EAR approximation (3) is bounded as follows

$$
E A R_{\min } \leq E A R_{\text {proxy }} \leq E A R_{\max }
$$

where

$$
\begin{aligned}
& E A R_{\min }=r+\frac{N P V_{\text {Extra costs }}(r)}{F \cdot D_{F}+C \cdot D_{\text {Extra costs }}} \text { with } D_{\text {Extra costs }}=\frac{n}{1+r} \text { and } \\
& E A R_{\text {max }}=r+\frac{N P V_{\text {Extra costs }}(r)}{F \cdot D_{F}} \text { since } D_{\text {Extra costs }}=0 .
\end{aligned}
$$

Proof. See the proof in Appendix B.

COROLLARY 1. The lower-bound $E A R_{\min }$ and the upper-bound $E A R_{\max }$ for the EAR approximation (3) occur if extra-costs are paid in a lump sum at the final time $n$ and at the initial time 0 , respectively.

\section{Numerical Illustrative Examples}

In this section, we develop a sensitivity analysis of the impact of the extra-costs payment timing on the EAR. Without loss in generality, we consider credit contracts with level payments of equal amount $f_{s}=f$, at all times $s=1, \ldots, n$. So, the Modified Duration $D_{F}$ of the credit cash flow $F$ is given by Equation (4) where $D_{F}$ depends only on the financing interest rate $r$ and the contract lifetime $n$, but not on the amount of the initial debt $F$.

Let us assume $F=150000, c_{0}=1000, N P V_{\text {Extra costs }}(r)=c_{0}+C=5000$ and, in accordance to the current observed rates, the annual compound financing interest rate of 5.0875\% and the equivalent monthly compound financing interest rate of $0.4143813 \%$, i.e., $r=0.004143813$, referring hence to monthly payments on the debt financing. If we suppose a contract lifetime of $n=24$ months, then $D_{F}=12.2511$.

Let the extra-costs be a lump sum paid at the time $s$ so that $D_{\text {Extra costs }}=\frac{s}{1+r}=\frac{s}{1.004143813}$ corresponding to times $s=0,6,12,18,24$.

Example 1.

Due to Theorem 1, the EAR decreases as $D_{\text {Extra-costs }}$ lengthens.

Table 1. EAR and $D_{\text {Extra-costs }}$

\begin{tabular}{clll}
\hline$s$ & $D_{\text {Extracosts }} \begin{array}{l}\text { Exact effective monthly interest } \\
\text { rate }\end{array}$ & $\begin{array}{l}\text { Estimated effective monthly interest } \\
\text { rate }\end{array}$ \\
\hline 0 & 0 & $0.69299 \%$ & $0.68647 \%$ \\
6 & 5.9752 & $0.68928 \%$ & $0.68297 \%$ \\
12 & 11.9505 & $0.68572 \%$ & $0.67957 \%$ \\
18 & 17.9257 & $0.68231 \%$ & $0.67625 \%$ \\
24 & 23.9010 & $0.67903 \%$ & $0.67301 \%$ \\
\hline
\end{tabular}

Example 2: Proxy accuracy

To highlight the accuracy of the periodic - monthly, in the examples - interest rates obtained with the EAR approximation in Equation (3), we compare these results to the yearly reference rates. 
Table 2. EAR exact - proxy spread

\begin{tabular}{rlll}
\hline \multicolumn{1}{c}{$s$} & $\begin{array}{l}\text { Exact } \\
\boldsymbol{E A R}\end{array}$ & Proxy EAR & $\begin{array}{l}\boldsymbol{E} \boldsymbol{A} \boldsymbol{R} \\
\text { spread }\end{array}$ \\
\hline 0 & $8.640 \%$ & $8.556 \%$ & $0.08444 \%$ \\
6 & $8.592 \%$ & $8.511 \%$ & $0.08157 \%$ \\
12 & $8.546 \%$ & $8.467 \%$ & $0.07958 \%$ \\
18 & $8.502 \%$ & $8.424 \%$ & $0.07836 \%$ \\
24 & $8.460 \%$ & $8.382 \%$ & $0.07783 \%$ \\
\hline
\end{tabular}

Note. Data confirm the precision of the EAR approximation compared with the EAR exact value

\section{Conclusions}

In this note, we analytically approximate the consumer credit $E A R$ with the financing contractual interest rate plus an extra-costs interest rate. Assuming that the due dated payments can be anticipated or postponed by discounting or accumulating, respectively, at the financing contractual interest rate, we analytically prove that $E A R$ decreases if the extra-costs payments are postponed. Therefore, the maximum EAR is achieved if the extra-costs are lump sum paid at the contract starting time and likewise the minimum EAR if the extra-costs are lump sum paid at the contract expiry date.

Another relevant result of this paper is to highlight how EAR depends on the timing of extra-costs payments. In fact, we prove that the extra-costs interest rate addendum in the approximation of $E A R$ not only depends on the Modified Duration of contractual payments linked to the repayment of the initial debt but also it depends on the Modified Duration of extra-costs payments distributed over time.

In particular, taking into account that Modified Duration measures the sensitivity of any series of cash flows to changes in the yield rate used to value series, we show that $E A R$ decreases with the increase in the Modified Duration of the cash flow of extra-costs.

To illustrate how our results can be applied to support the decision-makers in defining the structure of consumer credit loan payments to supervise the global cost of the financing, we develop a sensitivity analysis through numerical simulations in accordance to current observed rates consistent with the amount of the initial debt and a contract of 24 months lifetime. We consider consumer credit loans with level payments of equal amount and extra-costs paid in a lump sum at times ranging between the initial date and the expiry date of the contract. The numerical results show how the $E A R$ decreases as well as the estimate of the exact $E A R$ is increasingly precise as modified duration of extra-cost payments lengthens.

\section{Acknowledgments}

The authors are grateful to anonymous reviewers for their comments and suggestions. This work was supported in part by the Department of Management under a Grant of the MIUR (Ministero dell'Istruzione, dell'Università e della Ricerca Scientifica), Italy.

\section{References}

Brealey, R. A., Myers, S., \& Allen, F. (2014). The Principles of Corporate Finance (11th ed.). New York, NY: McGraw-Hill Irwin.

De La Grandville, O. (2003). Bond Pricing and Portfolio Analysis: Protecting Investors in the Long Run. Cambridge, Mass:The MIT Press Ltd.

Dierkes, T., \& Ortmann K. M. (2015). On the efficient utilisation of duration, Insurance: Mathematics and Economics, 60, 29-37. https://doi.org/10.1016/j.insmatheco.2014.11.002

Disney, R., \& Gathergood J. (2013). Financial literacy and consumer credit portfolios. Journal of Banking \& Finance, 37(7), 2246-2254. https://doi.org/10.1016/j.jbankfin.2013.01.013

Magni, C. A. (2020) Investment Decisions and the Logic of Valuation Linking Finance, Accounting, and Engineering, Switzerland AG: Springer Nature. https://doi.org/10.1007/978-3-030-27662-1

Norstrøm, C. J. (1972). A Sufficient Condition for a Unique Nonnegative Internal Rate of Return, Journal of Financial and Quantitative Analysis, 7(3), 1835-1838. https://www.jstor.org/stable/2329806 
Osborne, M. (2014). Is APR a Robust Measure of the Cost of Consumer Credit? Multiple Interest Rate Analysis: Theory and Applications. London: Palgrave Pivot. https://doi.org/10.1057/9781137372772_4

Shah, S., Sukmana, R., \& Fianto, B. (2020). Macaulay's theory of duration: 80-year thematic bibliometric review of the literature. Journal of Economic Studies. https://doi.org/10.1108/JES-11-2019-0540

\section{Notes}

Note 1. Due to Norstrøm (1972) condition, the $E A R$ is the unique solution of the equation $N P V_{\text {Global cost }}(x)=0$. By construction $N P V_{\text {Global cost }}(x)$ in (2) is a strictly increasing function in $x$

Note 2 . In the following, the term proxy is also used as shorthand by approximated measure.

\section{Appendix A Proof of Theorem 1}

Given the annual compound financing interest rate $r$, let us approximate the function $N P V_{\text {Global cost }}(x)$ in $(2)$ with Taylor polynomial approximation

$$
N P V_{\text {Global cost }}(x) \cong N P V_{\text {Global cost }}(r)+N P V_{\text {Global cost }}^{\prime}(r) \cdot(x-r) \text {. }
$$

where $N P V_{\text {Global cost }}^{\prime}(r)$ is the derivative of $N P V_{\text {Global cost }}$ with respect to $x$ at $x=r$.

Set $x=E A R$ then, by definition, $N P V_{\text {Global cost }}(E A R)=0$ and (A.1) can be solved for $E A R \neq r$ :

$$
E A R \cong r+\frac{-N P V_{\text {Global cost }}(r)}{N P V V_{\text {Global cost }}(r)}, \text { with } N P V^{\prime}{ }_{\text {Global cost }}(r) \neq 0
$$

For $x=r$, Equation (2) becomes

$$
\begin{aligned}
& N P V_{\text {Global cost }}(r)=N P V_{F}(r)-N P V_{\text {Extra costs }}(r)=0-N P V_{\text {Extra costs }}(r)= \\
& =-c_{0}-\sum_{s=1}^{n} \frac{c_{s}}{(1+r)^{s}}=-\left(c_{0}+C\right)
\end{aligned}
$$

where $C=\sum_{s=1}^{n} \frac{c_{s}}{(1+r)^{s}}$ is the present value of future extra-costs.

The derivative of (2) at $x=r$ can be reformulated as

$$
\begin{aligned}
& N P V^{\prime}{ }_{G} \text { lobal cost } \\
& =\frac{\sum_{s=1}^{n} s \cdot f_{s}(1+r)^{-s}}{(1+r)}+\frac{\sum_{s=1}^{n} s \cdot c_{s} \cdot(1+r)^{-s}}{(1+r)}=F \cdot D_{F}+C \cdot D_{\text {Extra costs }}
\end{aligned}
$$

where

- $D_{F}=\frac{\sum_{s=1}^{n} s \cdot f_{s} \cdot(1+r)^{-s}}{(1+r) \cdot \sum_{s=1}^{n} f_{s} \cdot(1+r)^{-s}}=\frac{\sum_{s=1}^{n} s \cdot f_{s} \cdot(1+r)^{-s}}{(1+r) \cdot F}$, with $\frac{1}{1+r} \leq D_{F} \leq \frac{n}{1+r}$, is the Modified Duration of the contract payback discounted at the financing interest rate $r$;

- $D_{\text {Extra costs }}=\frac{\sum_{s=1}^{n} s \cdot c_{s} \cdot(1+r)^{-s}}{(1+r) \cdot \sum_{s=1}^{n} c_{s} \cdot(1+r)^{-s}}=\frac{\sum_{s=1}^{n} s \cdot c_{s} \cdot(1+r)^{-s}}{(1+r) \cdot C}$ is the Modified Duration of the extra-costs at the 
financing interest rate $r$ and there exists at least one $c_{s} \neq 0$, with $s=1, \ldots, n$, and $\frac{1}{1+r} \leq D_{\text {Extra costs }} \leq \frac{n}{1+r}$; and

- $\quad D_{\text {Extra costs }}=0$ if $c_{s}=0$ for all $s=1, \ldots, n$.

Let $E A R \neq r$ be and substitute the expressions of $N P V_{\text {Global cost }}(r)$ and $N P V_{\text {Global cost }}^{\prime}(r)$ with $N P V_{\text {Global cost }}^{\prime}(r) \neq 0$ in Equation (A.2). Since $N P V_{\text {late }}^{\prime}(r)$ is a sum of positive addenda, by Equation (A.3) and Equation (A.4) we obtain

$$
E A R \cong r+\frac{-N P V_{\mathrm{G} \text { lobal cost }}(r)}{N P V^{\prime} \mathrm{G}_{\text {lobal cost }}(r)}=r+\frac{c_{0}+C}{F \cdot D_{F}+C \cdot D_{\mathrm{Extra} \text { costs }}}
$$

where $N P V_{\text {Global cost }}(r)=-\left(c_{0}+C\right)=-N P V_{\text {Extra cost }}(r)$.

\section{Appendix B Proof of Theorem 2}

Let $N P V_{\text {Extra costs }}(r)=c_{0}+C$ be fixed. The extra-costs addendum defined in Equation (3)

$$
\varepsilon=\varepsilon\left(D_{\text {Extra costs }}\right)=\frac{N P V_{\text {Extra costs }}(r)}{F \cdot D_{F}+C \cdot D_{\text {Extra costs }}}
$$

is a decreasing function in $D_{\text {Extra costs }}$. Then it follows that the minimum of $\varepsilon=\varepsilon\left(D_{\text {Extra costs }}\right)$ occurs if $D_{\text {Extra costs }}=\frac{n}{1+r}$ and the maximum if $D_{\text {Extra costs }}=0$.

\section{Copyrights}

Copyright for this article is retained by the authors, with first publication rights granted to the journal.

This is an open-access article distributed under the terms and conditions of the Creative Commons Attribution license (http://creativecommons.org/licenses/by/4.0/). 